\title{
Analysing the Impact of Horizontal Shading Device - A Case of Octagonal Shape Building
}

\author{
Kirthi Chandra ${ }^{1}$, G. Rajeev ${ }^{2}$, A. Rupendar ${ }^{3}$, Y. Sai Udeep ${ }^{4}$, V. Praseeda ${ }^{5}$, V. GunaShekar ${ }^{6}$, K. Rushika ${ }^{7}$, \\ M. Sowmya ${ }^{8}$
}

Assistant Professor, Department of Architecture, Vaishnavi School of Architecture and Planning, Hyderabad, India ${ }^{1}$

Student, Department of Architecture, Vaishnavi School of Architecture and Planning, Hyderabad, India ${ }^{2,3,4,5,6,7,8}$

\begin{abstract}
Daylight is one of the important factors improving the quality of lifestyle and efficient building ergonomics. There are many software and websites, which provide us stereographic projections of any region at any geographical locations. These charts support us to understand solar azimuth and solar altitude angle and generate shadow angles at any specific time and month of the year. The selected study area is Hyderabad, India and the conclusions derived are the dimensions of horizontal shading devices as sunshades. The aim of this study is to derive and set standard horizontal shade devices in cardinal directions and inter-cardinal directions, which can provide shade for the window without allowing any direct sunlight to enter the building in selected site region. The limitation considered is the azimuth angle, which is to be a minimum and maximum angle for any month in every particular cardinal and intercardinal direction, and the altitude angle is considered minimum angle in the duration of 9:00 to 16:00 hours from the year 2016. This horizontal shading device would guide a metropolitan city to implement efficient shading device.
\end{abstract}

Keywords: Horizontal Shading device, sun azimuth and altitude angles, building orientation.

\section{INTRODUCTION}

Building industry, which started ages ago as shelter from The present Indian population is 1.21 Billion (India, various environmental factors and now stand not only as a CensusInfo India 2011, 2016) and the newly formed necessity but also an icon of strength. In today's context Telangana State is populated by 35 million (Hyderabad, building industry uses $40 \%$ of global energy and global 2014), which is $2.89 \%$ of India's population. The capital resources (United Nations Environment Programme, city of Telangana is Hyderabad, which has the population 2009).

At International level, there are always been questions raised for net zero energy building construction (Mansi Jain, 2016). Even the solar geometry, sun path, orientation of the building and other daylight factors are a part of cost effective and energy efficient design. Better lighting not only saves electricity but also lowers wastage, which ultimately makes the building sustainable (workshop, 2015).

Understanding sun angles is very important for day lighting but also for producing heat energy. This can develop suitable sun collectors which can work efficiently for different locations by using tilt angles for exampleAustria and Germany which produces $35,00,000 \mathrm{~m} 2$ and $1,20,00,000 \mathrm{~m} 2$ of heat energy from understanding variation in tiltation of sun angles (Istvan Patko, 2013). Photovoltaic Thermal (PVT), which is latest sun collectors, works efficiently to $13.7 \%$ to utilize the maximum fixed sun inclination for solar panel (Joao Gomesa, 2013). Solar sun collectors are to be changed orientation for every month (Basharat Jamil, 2016). There are certain miscalculations for finding the exact angle of incidences. Suns angle of incidence is generally considered as parallel but there will be $9 \%$ error in its efficiency (Maxime Mussard, 2014). of 68,09,970 (India, Bhuvan-Indian Geo Platform of ISRO, 2016) and 8,49,051 numbers of houses recorded (Hyderabad, 2014). The government of India has proposed 20 Smart cities. The core infrastructure elements in a Smart City would include adequate water, electricity, solid waste management, transport facility, housing for poor, connectivity, digitalization, e-governance, sustainable environment, Health, education, development and safety of citizens especially women, children and elderly. It has always been a criterion under city level evaluation to summarize one of the key impacts as sustainability and inclusiveness in cost effective design for the housing (Development, 2015).

There are different philosophies, which connect the sustainability and daylight factors. Three-tier Design is one which approach for cooling a building are Mechanical cooling, passive cooling and Shading \& Light colours (Lechner, 2009). Some of the researchers have concluded that the buildings with octagon shapes and are aligned to North Direction is majorly exposed to certain directions which can be exposed to sunlight for a longer duration when compared to other direction like southwest, southeast and south direction (Amita maurya, 2012).

The slope of the land is another factor, which can change the angle of incidence. Some examples, relating sustainability to the daylighting are Mitza Ramon- was 


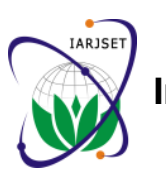

IARJSET

Vol. 4, Issue 1, January 2017

showing that frontal orientation of the building on the All the openings are with wood or aluminium panel. southeast side and the longitudinal towards east-west Hyderabad has more than 8,00,000 dwellings recorded orientation. Bidani House, Faridabad, India has composite including individual housing, apartments, villas, etc., climate is another example for usage of double heights, (Hyderabad, 2014).

multiple terraces and louvered openings in which south east side is ideal for maximum exposure.PEDA, office complex, Chandigarh, India is in composite climate context which has terraced building skin towards south/ southeast edges by gradually scaling down the building in mass and volume (Arvind Krishna, 2001).

\section{DATA AND METHODOLOGY}

The Study is based on the stereographic chart produced from Latitude and Longitude location and Coordinated Universal Time (UTC), which is $17.5^{\circ} \mathrm{N}$ Latitude and There are standards, which specify that the length of the $78.5^{\circ}$ E Longitude along the UTC is 5:30 (Frank Vignola, sunshade should be a multiple of $1 \mathrm{~m}$ and the projection 2015). This stereographic chart is further divided into four should be multiple of $0.5 \mathrm{~m}$ (Standards, 2005). These would support the design but on a broader aspect in site context at the national level in India. It would be much more preferable if there are regional standards since India has diversified tropical climates. This article is an attempt to explore the horizontal shading devices for Hyderabad region in 8 cardinal and inter-cardinal directions.

\section{STUDY AREA}

A. Location and Climate

Hyderabad is at $17.5^{\circ} \mathrm{N}$ Latitude and $78.5^{\circ} \mathrm{E}$ Longitude lies in the northern hemisphere as per the sun's movement during summer solace, winter solace and equinox (M. Pramitha, 2015). This region is under Hot and Dry climate where the mean monthly temperature is $>30^{\circ} \mathrm{C}$. Its relative humidity is $<55 \%$ and Precipitation $>5 \mathrm{~mm}$. This has more than 20 days of clear days (Arvind Krishna, 2001). The hot and dry climate of this region requires the built structure to be efficiently cross ventilated.

\section{B. Building Materials}

Buildings in Hyderabad are constructed with Reinforced Cement Concrete as roof covering and the brick walls along with plastering on all sides. cardinal and four inter-cardinal directions providing us with North, North East, East, South East, South, South West, West and North West. Here each wall for an octagonal shape building should change its direction at $45^{\circ}$. The timeline and month line guides us to divide the sun path diagram into 8 parts.(Arvind Krishna, 2001).

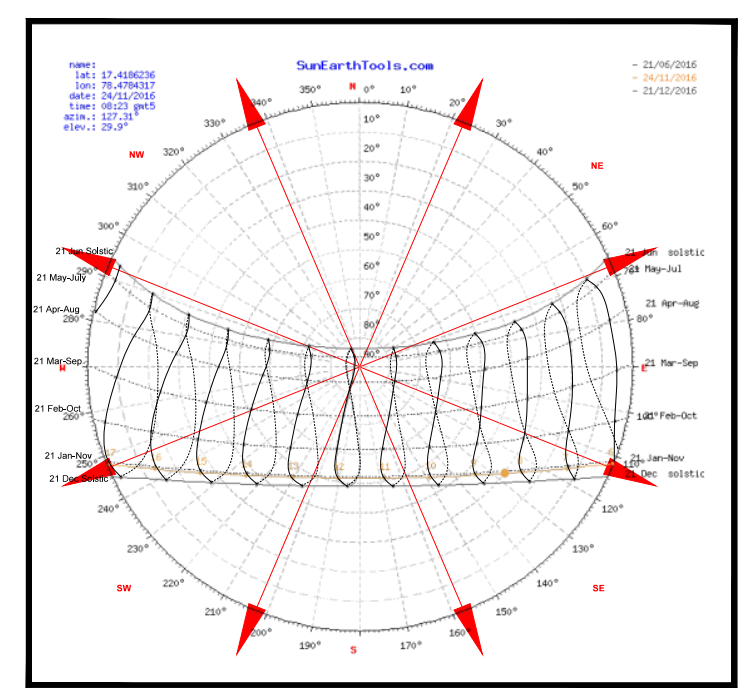

Fig. 1. Stereographic Chart 8 directions (Frank Vignola, 2015)

TABLE I AZIMUTH AND ALTITUDE ANGLES

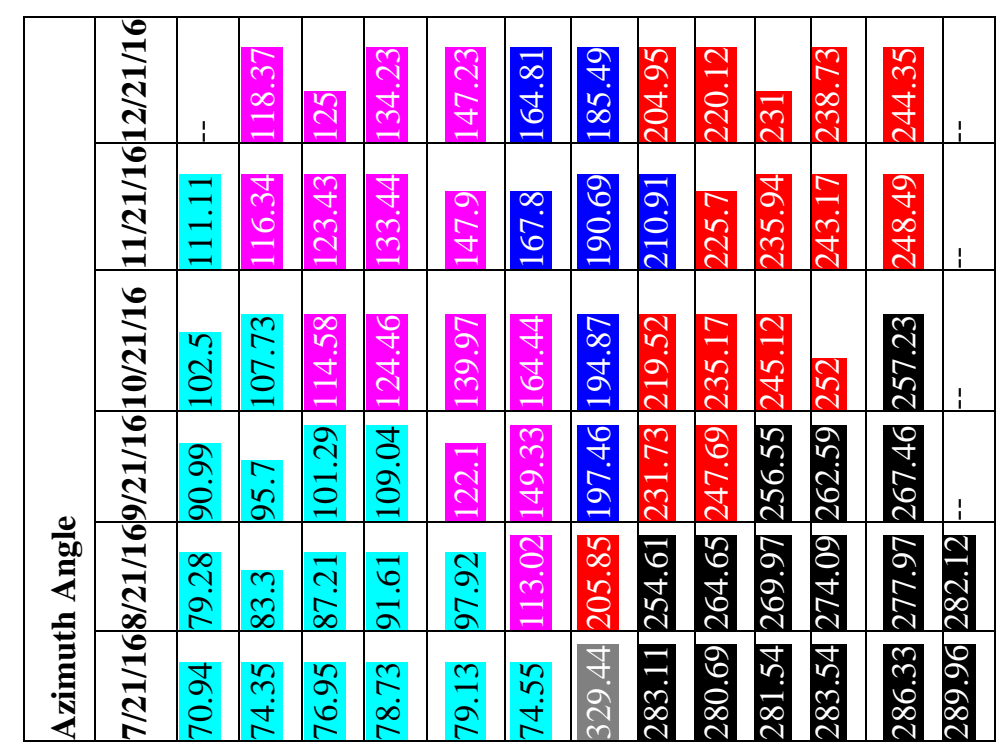


Vol. 4, Issue 1, January 2017
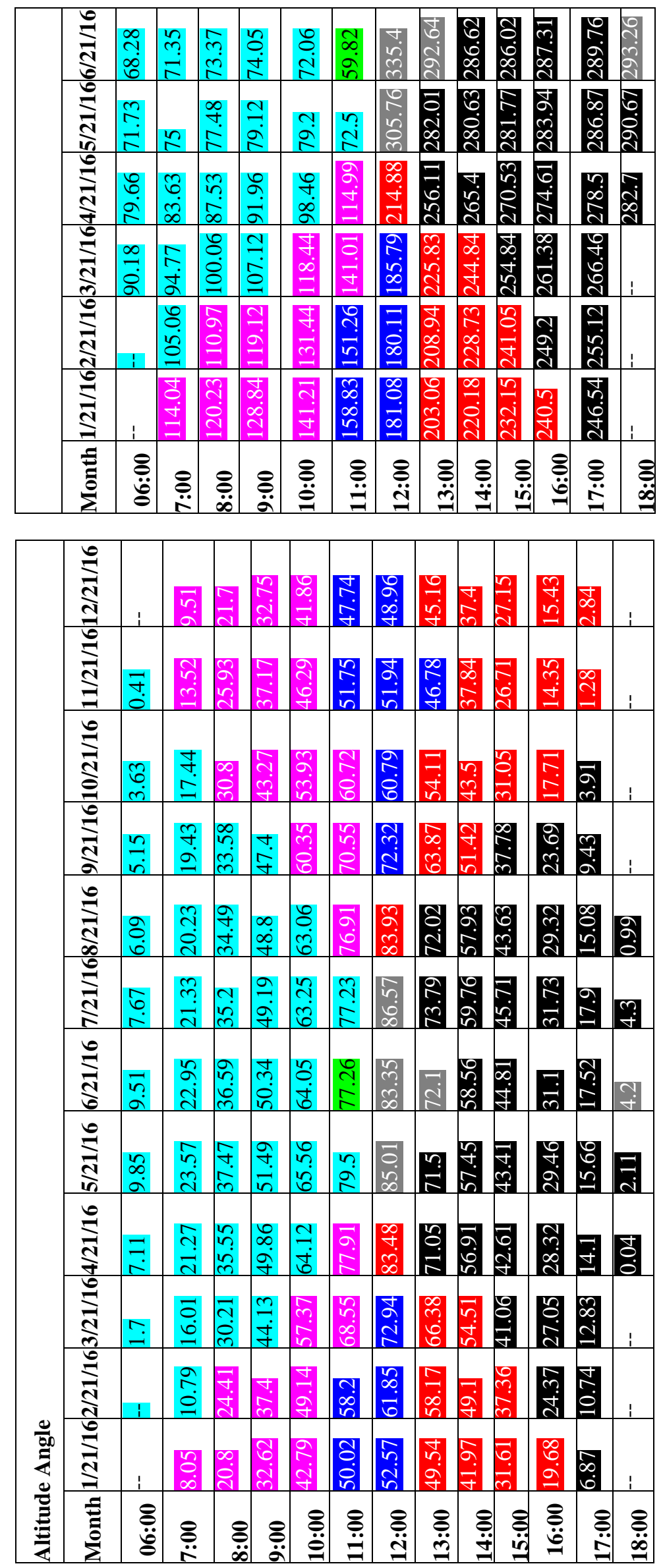
Vol. 4, Issue 1, January 2017

\section{IV.INFERENCES}

The recorded azimuth and altitude angle can be tabled to get the minimum and the maximum azimuth and minimum altitude angle from 9:00 to 16:00 Hours in all the 8 directions throughout the year. Here in Table II, the north-facing wall does not receive $23.69^{\circ}$. any direct sunlight. Altitude angle is the angle, which guides the extension of shading device from the wall surface. In the northeast and northwest, the horizontal shading device is so less projected that we had to place to the least projections resulting that the northeast would have the altered altitude angle. The minimum altitude angle is at south and southwest which is $14.35^{\circ}$ and

TABLE II MAXIMUM AND Minimum AZIMUTH AND ALtiTudE ANGLES

\begin{tabular}{|l|l|l|l|l|}
\hline \multirow{2}{*}{ S. No. } & \multirow{2}{*}{ 8 Cardinal Direction } & \multicolumn{2}{|l|}{ Azimuth Angle } & Altitude Angle \\
\cline { 3 - 5 } & & Minimum (A) & Maximum (B) & Minimum after 9:00 and before 16:00 \\
\hline 1 & North & -- & -- & -- \\
\hline 2 & North East & 59.82 & 59.82 & 77.26 \\
\hline 3 & East & 68.28 & 111.11 & 44.13 \\
\hline 4 & South East & 110.97 & 164.44 & 32.62 \\
\hline 5 & South & 151.26 & 210.91 & 46.78 \\
\hline 6 & South West & 203.06 & 252 & 14.35 \\
\hline 7 & West & 246.54 & 290.67 & 23.69 \\
\hline 8 & North West & 292.64 & 335.4 & 72.1 \\
\hline
\end{tabular}

\section{SHADOW ILLUSTRATION}

To illustrate the above inference, we would consider a wall of $3 \mathrm{~m}$ wide and $3 \mathrm{~m}$ heights with the window size is $1.2 \mathrm{~m} \mathrm{X} 1.2 \mathrm{~m}$ and the top sill level as $0.8 \mathrm{~m}$ at 8 different directions of an octagonal shape building. This octagonal shape is considered based on cardinal and inter-cardinal directions. The shading devices can be of any shape and size based on the decision maker's requirement. Generally, there are three shade devices, which are horizontal shading devices, vertical shading devices, and Egg-crate devices. These are derived from the shadow angles (Azimuth and Altitude) from stereographic Charts at their respective latitudes on the globe (O H Koenigsberger, 2011).

In the below illustration, the Section and Plan for every direction representing the inside and outside of the building along with dimension in the section and extension of sunshade with minimum (A) and maximum (B) azimuth angle are given
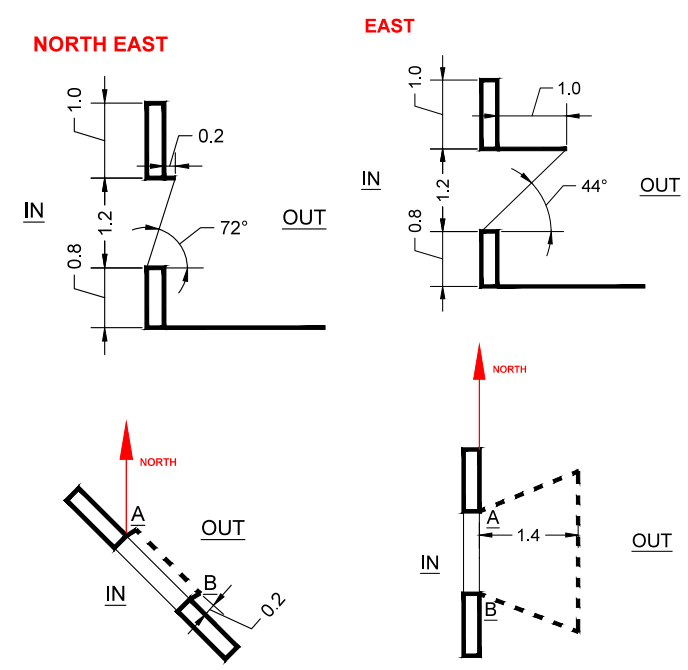

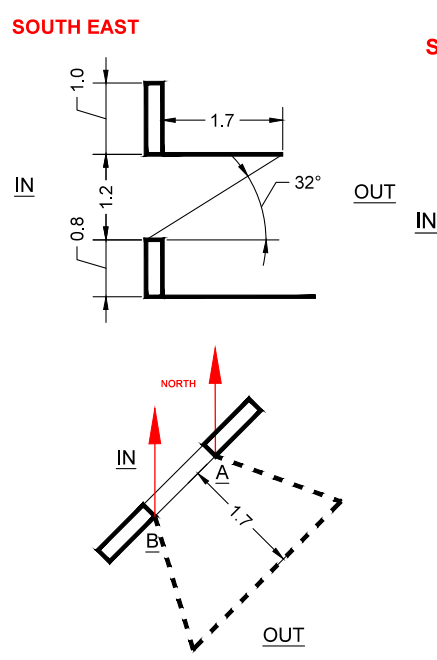

SOUTH $\underline{\mathrm{IN}}$
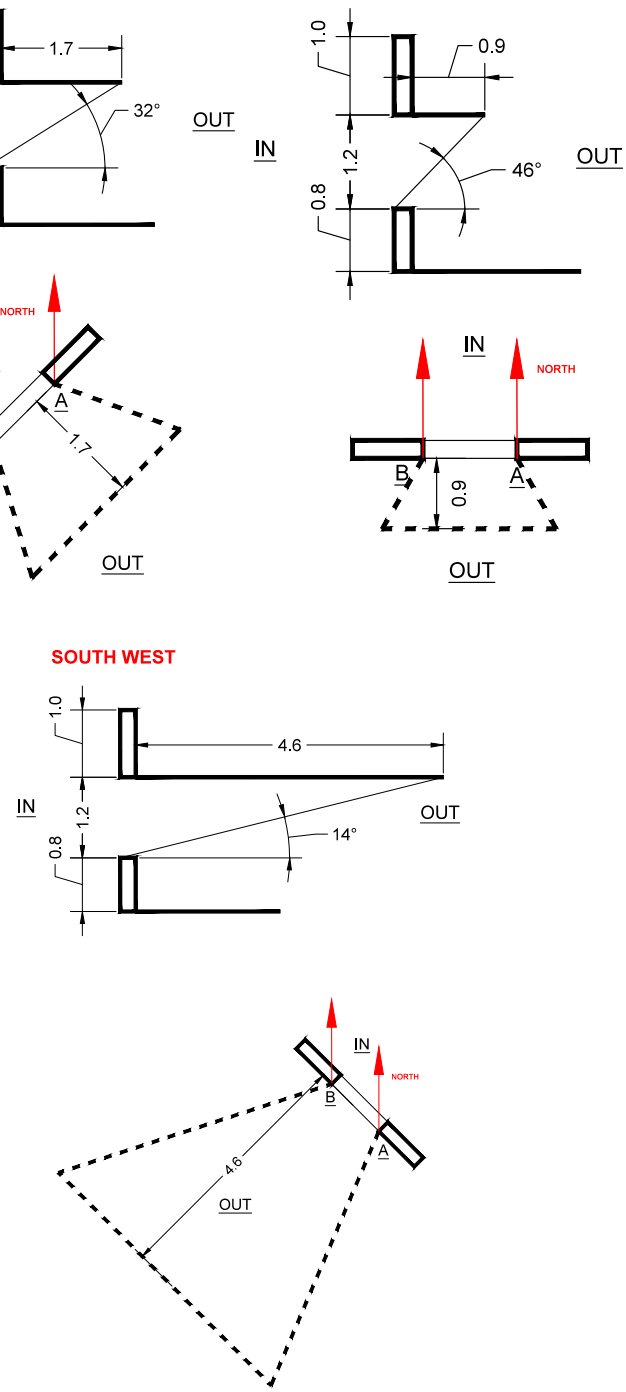
Vol. 4, Issue 1, January 2017

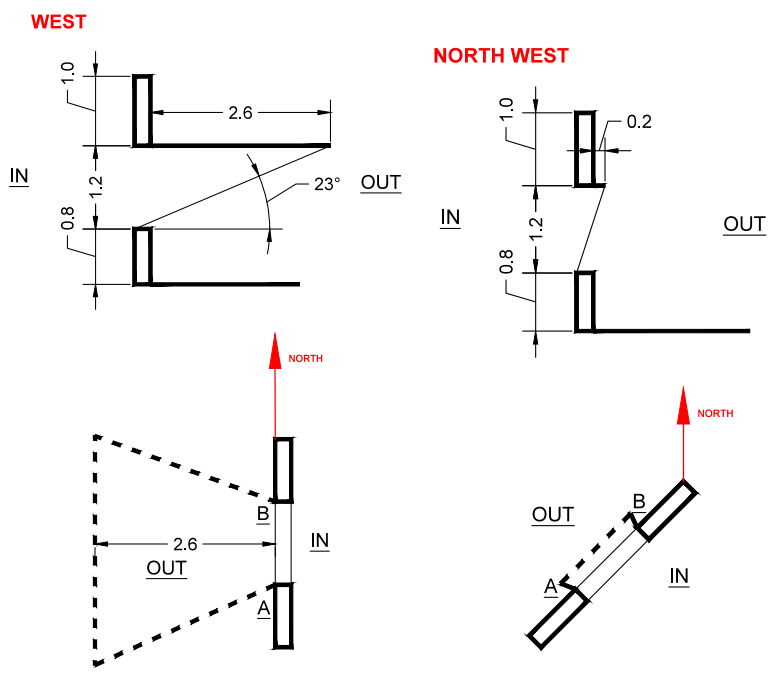

Fig. 2. Plan and Section at all the 7 cardinal directions representing at dimensions and projections of sunshade

\section{VI.CONCLUSION}

The Southwest direction of the building requires the $4.6 \mathrm{~m}$ maximum extension of sunshade when compared to any other direction whereas west and southeast requires the second and third maximum extension of about $2.6 \mathrm{~m}$ and $1.7 \mathrm{~m}$.

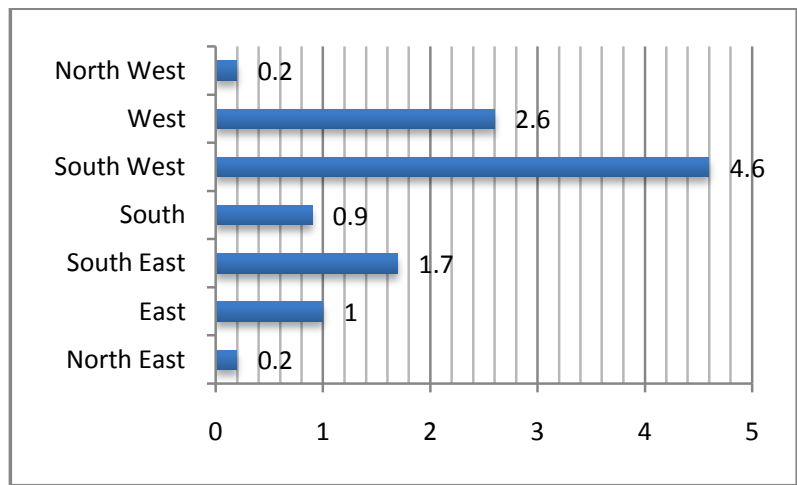

Fig. 3. Required Projection from the outer surface of the wall (in Meters)

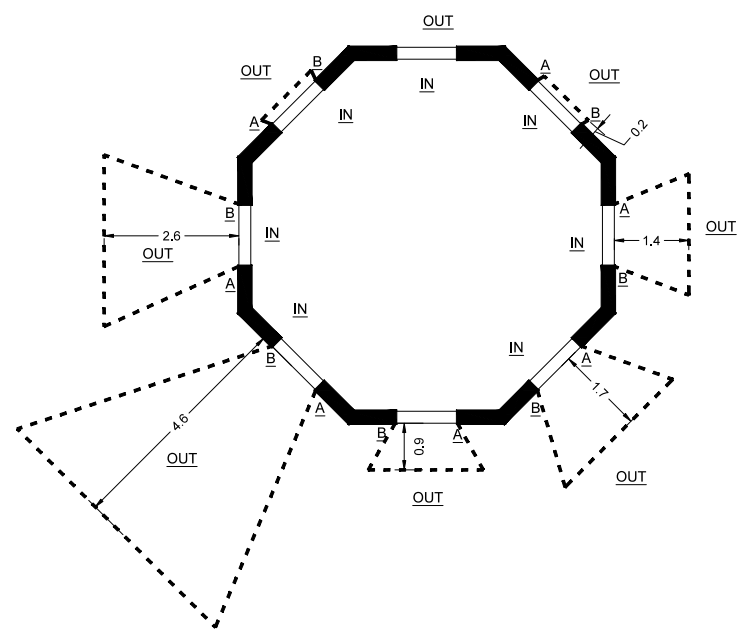

Fig. 4. Plan representing sunshade for all the directions
The east and the south require about $1.4 \mathrm{~m}$ and $0.9 \mathrm{~m}$ extensions respectively. The northeast and northwest require about $0.2 \mathrm{~m}$ extension and the north does not require any shading device.

This would show that the North, North-East, South, NorthWest $(0-1.0 \mathrm{M})$ would require less projection, East, South-East, West would require normal Projection (1.0 $3.0 \mathrm{M})$ and South West would require maximum projection for providing sunshade $(>3 \mathrm{M})$.

\section{REFERENCES}

[1] United Nations Environment Programme. (2009). Building and Climate Change - Summary for decision makers. France: United Nations Environment Programme.

[2] Workshop, A. s. (2015, July 9). Sustainable Workshop. Retrieved Dec 22, 2016, from https://sustainabilityworkshop.autodesk.com/ contributors:https://sustainabilityworkshop.autodesk.com/buildings/ lighting-and-daylighting-design

[3] Amita maurya, U. B. (2012). Evaluation of Suitable Vertical and Horizontal Shadow Angles for Shading Devices at Mumbai, India. People's Journal of Science \&Technology , 27-34.

[4] Arvind Krishna, S. Y. (2001). Climate Responsive Architecture-A Design Handbook for Energy Efficient Building. New Delhi, India: McGraw Hill Education (India) Private Limited.

[5] Basharat Jamil, A. T. (2016). Estimation of solar radiation and optimum tilt angles for south-facing surfaces in Humid Subtropical Climatic Region of India. Engineering Science and Technology, an International Journal, 1826-1835.

[6] Development, M. o. (2015). Smart Cities Mission. Retrieved from http://smartcities.gov.in/:

http://smartcities.gov.in/Cities_Profile.aspx

[7] Frank Vignola, R. K. (2015, December 2). http://solardat.uoregon. edu/PolarSunChartProgram.php. Retrieved December 1, 2016, from http://solardat.uoregon.edu/PolarSunChartProgram.php: http://solardat. uoregon.edu/download/temp/37736545.pdf

[8] India, G. o. (2016, Aug 16). Bhuvan-Indian Geo Platform of ISRO. Retrieved Dec 21, 2016, from http://bhuvan.nrsc.gov.in/bhuvan_li nks.php\#:http://bhuvan.nrsc.gov.in/urban/sprawl/urbangrowth.php\#

[9] India, G. o. (2016). CensusInfo India 2011. Retrieved Dec 21, 2016, from http://www.devinfo.org/indiacensuspca/libraries/ aspx/ Home. aspx: http://www.dataforall.org/dashboard/censusinfoindia_pca/

[10] Istvan Patko, A. S. (2013). Evaluation the impact tilt angle on the sun collectors. International Conference on Sustainable Energy Engineering and Application, $222-231$.

[11] Hyderabad, D. o. (2014). Statistical Year Book-2015. New Delhi: Directorate of Economics and Statistics.

[12] Joao Gomesa, L. D. (2013). Minimizing the Impact of Shading at Oblique Solar Angles in a Fully Enclosed Asymmetric Concentrating PVT Collector. ISES Solar World Congress, 2176 2185.

[13] Lechner, N. (2009). Heating, Cooling, Lighting-Sustainable Design Methods for Architects. New Jersey: John Wiley \& Sons, Inc.,.

[14] M. Pramitha, M. V. (2015). Evidence for tropospheric wind shear excitation of highphase-speed gravity waves reaching the mesosphere using the ray-tracing technique. Atmospheric Chemistry and Physics , 2709-2721.

[15] Maxime Mussard, O. J. (2014). Influence of solar tracking inaccuracy and sun rays modeling on the efficiency of a small-scale parabolic trough. ISES Solar World Congress , 1508 - 1515.

[16] Mansi Jain, T. H. (2016). Analyzing sectoral niche formation: The case of net-zero energy buildings in India. Environmental Innovation and Societal Transitions.

[17] H Koenigsberger, T. G. (2011). Manual of Tropical Housing and Building-Climate Design. Hyderabad: Universities Press (India) Private Limited.

[18] Standards, B. o. (2005). NATIONAL BUILDING CODE OF INDIA 2005. New Delhi: BUREAU OF INDIAN STANDARDS. 